\title{
Original
}

\section{JM-1232(-) and propofol, a new combination of hypnotics with short-acting and non-cumulative preferable properties}

\author{
Saori TAHARABARU ${ }^{1,2)}$, Takahiro TAMURA ${ }^{3)}$, Michiko HIGASHI ${ }^{4)}$, Naoyuki MATSUDA ${ }^{4)}$, \\ Maiko SATOMOTO ${ }^{5)}$, Yushi U. ADACHI ${ }^{6)}$, Aiji Boku $\mathrm{SATO}^{2)}$ and Masahiro OKUDA ${ }^{2)}$ \\ 1) Department of Anesthesia, Nishio Municipal Hospital, Nishio Municipal Hospital, 6 Kamiawahara, Kumami-cho, Nishio, \\ Aichi 4458510, Japan \\ ${ }^{2)}$ Department of Anesthesiology, Aichi Gakuin University School of Dentistry, 2-11 Suemori-dori, Chikusa-ku, Nagoya, Aichi \\ 4658651, Japan \\ 3) Department of Surgical Intensive Care Medicine, Nagoya University Hospital, 65 Tsurumai-cho, Showa-ku, Nagoya, Aichi \\ 4668550, Japan \\ 4) Department of Emergency \& Critical Care Medicine, Nagoya University Graduate School of Medicine, Nagoya University \\ Hospital, 65 Tsurumai-cho, Showa-ku, Nagoya, Aichi 4668550, Japan \\ ${ }^{5)}$ Department of Anesthesiology, Toho University School of Medicine, Toho University Medical Center, Ohmori Hospital, \\ 6-11-1 Ohmori-Nishi, Ohta-ku, Tokyo 1438541, Japan \\ ${ }^{6)}$ Department of Anesthesia and Intensive Care Medicine, International University of Health and Welfare, 537-3 Iguchi, \\ Nasushiobara, Tochigi 3292763, Japan
}

\begin{abstract}
Drug interactions are significant in anesthesiology because drug combinations can potentially possess novel properties. The pharmacological advantages of a new combination of the benzodiazepine receptor agonist $\mathrm{JM}-1232(-)$ and propofol were investigated in mice. Male adult mice were administered JM-1232(-) or propofol or combinations of the two drugs intravenously. Loss of the righting reflex was evaluated as achieving hypnosis, and the time until recovery of the reflex was measured as hypnosis time. After determining the $\mathrm{ED}_{50}$, doses double and triple the $\mathrm{ED}_{50}$ of propofol were injected with $\mathrm{JM}-1232(-)$ to compare hypnosis time. The injections were repeated four times, and the hypnosis times were compared. Flumazenil was administered separately immediately after the last dose was injected. The $\mathrm{ED}_{50}$ values ([95\% confidence interval]) for hypnosis were 3.76 [3.36-4.10] for JM$1232(-)$ and 9.88 [8.03-11.58] mg kg-1 for propofol. Co-administration of 0.5 and $1 \mathrm{mg} \mathrm{kg}^{-1} \mathrm{JM}-1232(-)$ reduced the $\mathrm{ED}_{50}$ values of propofol to 1.76 [1.21-2.51] and 1.00 [0.46-1.86] mg kg-1, respectively. The drug combination for hypnosis produced a supra-additive interaction. Hypnosis time was significantly shorter in the groups given the mixtures compared to each hypnotic administered alone. After repeated injections, hypnosis time with the mixtures showed smaller prolongation than that with the hypnotic alone. Flumazenil completely restored the recovery time after anesthesia. The combination of $\mathrm{JM}-1232(-)$ and propofol showed a supra-additive interaction, and the reduced hypnotic dose contributed to a faster recovery even after multiple injections.
\end{abstract}

Key words: hypnotics, flumazenil, JM-1232(-), propofol, supra-additive interaction

\section{Introduction}

$\mathrm{JM}-1232(-)$ is an isoindoline derivative developed in Japan and potential anesthetic with a short duration of action $[1,2]$. JM-1232(-) is water soluble and is highly potent. Although the molecular structure of JM-1232(-) is different from classical and typical benzodiazepines, JM-1232(-) enhances synaptic inhibition by modulating

(Received 4 June 2020 / Accepted 10 September 2020 / Published online in J-STAGE 16 October 2020)

Corresponding author: Y.U.Adachi.e-mail: yuadachi@iuhw.ac.jp

This is an open-access article distributed under the terms of the Creative Commons Attribution Non-Commercial No Derivatives (by-nc-nd) License <http://creativecommons.org/licenses/by-nc-nd/4.0/>.

(C)2021 Japanese Association for Laboratory Animal Science 
benzodiazepine binding sites on $\gamma$-aminobutyric acid A receptors, similar to benzodiazepine derivatives [3]. The characteristics of JM-1232(-) might be suitable for supporting not only laboratory experiments but also clinical anesthesia and intensive care [4]. JM-1232(-) has been administered to humans as "MR04A3," and demonstrated favorable and acceptable profiles in a preclinical trial [5].

Propofol is one of the most popular intravenous anesthetics in daily clinical practice [6] including veterinary medicine. The characteristics of propofol, including rapid onset and prompt recovery, make it an appropriate drug for general anesthesia. However, a long-lasting infusion of propofol might lead to prolongation of its effect and delay recovery [7]. The dose of propofol required to induce anesthesia can be reduced by a series of pre-medications $[8,9]$. Some of these drugs, such as benzodiazepine derivatives, significantly enhance the hypnotic activity of propofol $[10,11]$. Thus, co-administration of JM-1232(-) could reduce the required dose of propofol. Moreover, the reduced propofol dose might lead to further quick recovery. The new properties including more potent, faster recovery, less accumulative, may be preferable for achieving hypnosis during not only induction of anesthesia but also maintenance of sedation. The combination of other analgesics, including opioids, would provide more appropriate anesthetic conditions.

In the current study, the anesthetic properties of JM$1232(-)$ and propofol was evaluated in an in vivo investigation using mice. The induction and recovery profiles were investigated after repeated injections of the drug mixture, which simulated prolonged infusion. Finally, the animals were administered flumazenil to assess its antagonistic effects for recovery after long-lasting hypnosis.

\section{Materials and Methods}

\section{Animals}

After obtaining approval from the Ethics Committee for Animal Experiments at our institution (Final registration number: 26401), all experiments were performed in an animal laboratory. Male adult Deutsch-Denken-Yoken (ddY, closed colony) mice weighing 38 to $45 \mathrm{~g}$ (SLC Japan, Hamamatsu, Japan) were used. The animals were maintained on a 12/12-h light/dark cycle and fed ad libitum before the experiments. All experiments were conducted between 10 a.m. and 4 p.m. The mice were examined three times at most and had a recovery period of more than 7 days.

\section{Drugs}

Propofol (Diprivan, AstraZeneca K.K., Osaka, Japan) was diluted with $10 \%$ soybean oil (Intralipid, Otsuka Pharmaceutical Co., Ltd., Tokyo, Japan). JM-1232(-), which was provided as a gift from Maruishi Pharmaceutical (Osaka, Japan), was dissolved in physiological saline.

All solutions were mixed with the same volume of diluent and administered intravenously. Injection volume was set at $10 \mathrm{ml} \mathrm{kg}^{-1}$ in experiment 1 and at $5 \mathrm{ml} \mathrm{kg}^{-1}$ in experiments 2 and 3 . The experimental doses of JM1232(-), propofol, and the drug mixtures were calculated based on past and preliminary experiments $[12,13]$ (Table 1). The $\mathrm{ED}_{50}$ of propofol was first tested, and then other combinations were tried until all animals in the group showed the same response (hypnosis or not).

\section{Procedures}

The mice were set in a transparent animal holder to place a $24 \mathrm{G}$ plastic IV cannula (SurFlo, Terumo, Tokyo, Japan) into the tail vein. After confirming venous catheterization by checking the backflow of blood, another customized injection needle connected to a micro-sy-

Table 1. The percentage ratios of achieving hypnosis of responders in each treatment

\begin{tabular}{|c|c|c|c|c|c|c|c|c|c|}
\hline & \multicolumn{9}{|c|}{ Dose of JM-1232 $\left(\mathrm{mg} \mathrm{kg}^{-1}\right)$} \\
\hline & & & 3 & 3.5 & 4 & 4.5 & 5 & & \\
\hline \multirow[t]{3}{*}{ JM-1232(-) alone } & & & 0 & 33 & 83 & 83 & 100 & & \\
\hline & \multicolumn{9}{|c|}{ Dose of propofol $\left(\mathrm{mg} \mathrm{kg}^{-1}\right)$} \\
\hline & 0.625 & 1.25 & 2.5 & 3.75 & 5 & 7.5 & 10 & 12.5 & 15 \\
\hline Propofol alone & & & & & 0 & 17 & 67 & 67 & 100 \\
\hline \multicolumn{10}{|l|}{ Combination of Propofol and JM-1232(-) } \\
\hline $\mathrm{JM}-1232(-) 0.5 \mathrm{mg} \mathrm{kg}^{-1}$ & 0 & 33 & 83 & 100 & & & & & \\
\hline $\mathrm{JM}-1232(-) 1.0 \mathrm{mg} \mathrm{kg}^{-1}$ & 50 & 50 & 100 & & & & & & \\
\hline $\mathrm{JM}-1232(-) 2.0 \mathrm{mg} \mathrm{kg}^{-1}$ & 83 & 100 & 100 & & & & & & \\
\hline
\end{tabular}

The ratios of responders to total number of animals $(n=6)$ are expressed as the percentage $(\%)$. 
ringe was set into the plastic cannula, and the prepared material was quickly injected over 2-3 s. If the injection was irregular and incomplete, such as being resistant or showing extravasation, the mouse was omitted from the study. Mice were released from the animal holder and individually evaluated for hypnosis on a flat heated $\left(35^{\circ} \mathrm{C}\right)$ table by another observer. The criterion for hypnosis was loss of the righting reflex, occurring $<10 \mathrm{~s}$ after the start of the injection $[12,13]$. When hypnosis was observed, the mice were gently placed in the lateral decubitus position until spontaneous recovery to the upright position, which was defined as the end of hypnosis. The time from the start of drug injection to the end of hypnosis was defined as hypnosis time. Hypnosis time was recorded in the laboratory room and was verified by another blinded technical assistant using recorded movies of the experiments on another day. After the experiments, all animals were killed with inhalation of pure carbon dioxide more than 5 min following to the regulation of our institute.

\section{Experiment 1: Interaction between JM-1232(-) and propofol}

Mice were given either JM-1232(-) $(3,3.5,4,4.5$, and $\left.5 \mathrm{mg} \mathrm{kg}^{-1}\right)$ or propofol $\left(5,7.5,10,12.5\right.$, and $\left.15 \mathrm{mg} \mathrm{kg}^{-1}\right)$ intravenously to determine the hypnotic effects of various doses of the drugs. Each group consisted of six animals. To evaluate the effect of the combination of JM1232(-) and propofol, other mice were simultaneously administered JM-1232(-) $\left(0.5,1\right.$, and $\left.2 \mathrm{mg} \mathrm{kg}^{-1}\right)$ and propofol $\left(0.625,1.25,2.5,3.75\right.$, and $\left.5 \mathrm{mg} \mathrm{kg}^{-1}\right)$.

\section{Experiment 2: Effect of multiple injections on hypnosis time}

Double and triple the $\mathrm{ED}_{50}$ doses of JM-1232(-) (7.52 and $11.3 \mathrm{mg} \mathrm{kg}^{-1}$ ), propofol (19.8 and $29.6 \mathrm{mg} \mathrm{kg}^{-1}$ ), and the mixtures $\left(0.5 \mathrm{mg} \mathrm{kg}^{-1} \mathrm{JM}-1232(-)\right.$ and 3.5 and $5.3 \mathrm{mg} \mathrm{kg}^{-1}$ propofol; $1.0 \mathrm{mg} \mathrm{kg}{ }^{-1} \mathrm{JM}-1232(-)$ and 2.0 and $3.0 \mathrm{mg} \mathrm{kg}^{-1}$ propofol) were administered. The doses were set as sufficient administration for achieving hypnosis in all animals. Each group consisted of six animals. Immediately after recovery of the righting reflex, the same dose of the anesthetic that had been administered was repeated. Four injections were given to each animal. Hypnosis time was measured after the injection.

\section{Experiment 3: Effect of flumazenil administered after multiple injections on hypnosis time}

After the same injections were performed as in experiment 2, the last (fourth) injection of the hypnotic drug was immediately followed by administration of 0.2 $\mathrm{mg} \mathrm{kg}{ }^{-1}$ flumazenil $\left(5 \mathrm{ml} \mathrm{kg}^{-1}\right)$. Each group consisted of six animals. Anesthesia time after the injection was measured and was compared with the results of experiment 2 .

\section{Statistical analysis}

The sample size of the study was determined following a previous investigation $[12,13]$. To analyze the $50 \%$ effective dose $\left(\mathrm{ED}_{50}\right)$ and the $95 \%$ confidence intervals (CIs) for loss of the righting reflex, we determined the number of animals that lost the righting reflex from the total that received an assigned pharmacological treatment and correlated the results with the probability of their being under hypnosis using nonlinear least-squares logistic regression. The results for the required propofol dose for each group are presented as the $\mathrm{ED}_{50}$ and $95 \%$ CI.

Hypnosis time is expressed as mean $\pm \mathrm{SD}$. Analysis of variance (ANOVA) was used to compare the hypnosis time among groups, and the Newman-Keuls post hoc multiple-comparison test was used when ANOVA showed a significant difference $(P<0.05)$. The validity of the multiple-comparison test was verified in the previous investigation in comparison with other tests including Tukey-Kramer method $[12,13]$. All calculations were performed using a statistical software package (SPSS 24, IBM Japan, Tokyo, Japan).

\section{Results}

The rate of successful injections was $85 \%$. Although a few animals showed signs of temporal respiratory depression (hypopnea) immediately after the injection, there was no animal death during the study.

\section{Experiment 1: Interaction between JM-1232(-) and propofol}

The percentage ratio of achieving hypnosis is shown in Table. The hypnotic dose was 3.76 [3.36-4.10] mg $\mathrm{kg}^{-1}\left(\mathrm{ED}_{50}\right.$ and $\left.[95 \% \mathrm{CI}]\right)$ for $\mathrm{JM}-1232(-)$ and 9.88 [8.03-11.58] mg kg-1 for propofol. Co-administration of $0.5,1$, and $2 \mathrm{mg} \mathrm{kg}^{-1} \mathrm{JM}-1232(-)$ reduced the hypnotic dose of propofol to 1.76 [1.21-2.51], 1.00 [0.46$1.86]$, and $0.44[-0.38-0.80] \mathrm{mg} \mathrm{kg}^{-1}$, respectively. The sums of the normalized doses of the mixtures [14] were $0.30,0.35$, and 0.54 , and all values were under 0.9 . The isobologram demonstrated that the $\mathrm{ED}_{50}$ plots of the combinations were below the additivity line (Fig. 1).

\section{Experiment 2: Effect of multiple injections on hypnosis time}

Animals who received JM-1232(-) alone and the JM- 


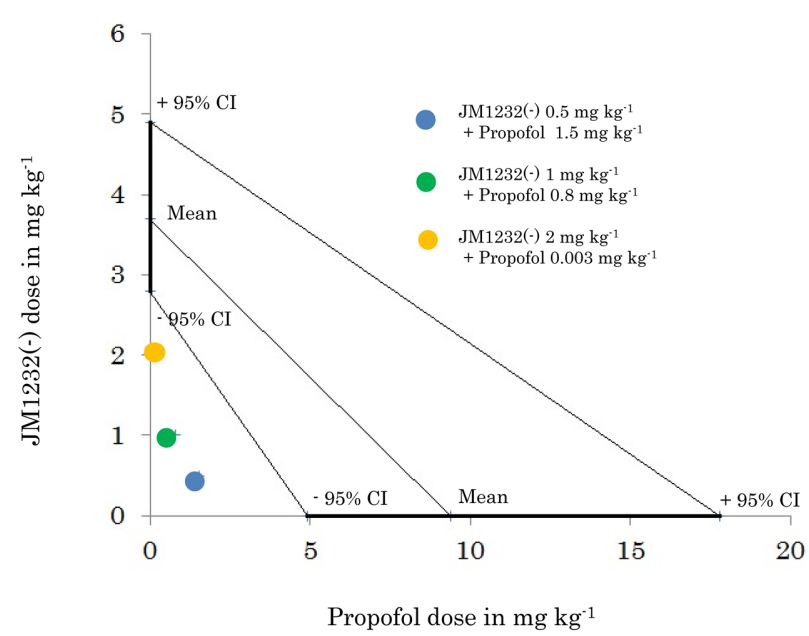

Fig. 1. Isobologram for the JM1232 (-) and propofol combination. CI: confidence interval.

1232(-)-propofol mixtures demonstrated significantly shorter recovery times after the first injection than those that received propofol alone at both double and triple the $\mathrm{ED}_{50}$ dose (Fig. 2). Hypnosis time was correlated with the dose in all groups. The prolongation of hypnosis time was correlated with repeated injections, except in the low-dose propofol group (Fig. 3). The prolongation was more apparent in the groups administered JM1232(-) alone.

\section{Experiment 3: Effect of flumazenil administered after the multiple injections on hypnosis time}

The hypnosis time of the first three injections in each group was consistent with the results of experiment 2 . Administration of flumazenil immediately after the fourth injection demonstrated no effect on the hypnosis time in the propofol alone groups, whereas the hypnosis times that had been extended by multiple injections of JM-1232(-) and the mixtures were significantly shortened by administration of flumazenil (Fig. 4).

\section{Discussion}

The present investigation demonstrated that the new combination of JM-1232(-) and propofol showed significant supra-additivity of the hypnotic effect with a shorter recovery time than either drug administered alone. Despite the high potency of the mixtures, prolongation of the hypnosis time after multiple repeated injections seemed to be negligible. Although the pharmacokinetic properties, i.e., the drug concentration, were not determined, the results were clearly demonstrated.

Drug interactions resulting from the pharmacokinetic and pharmacodynamic effects of drugs are one of the foci of anesthesiology $[14,15]$. General anesthesia con-

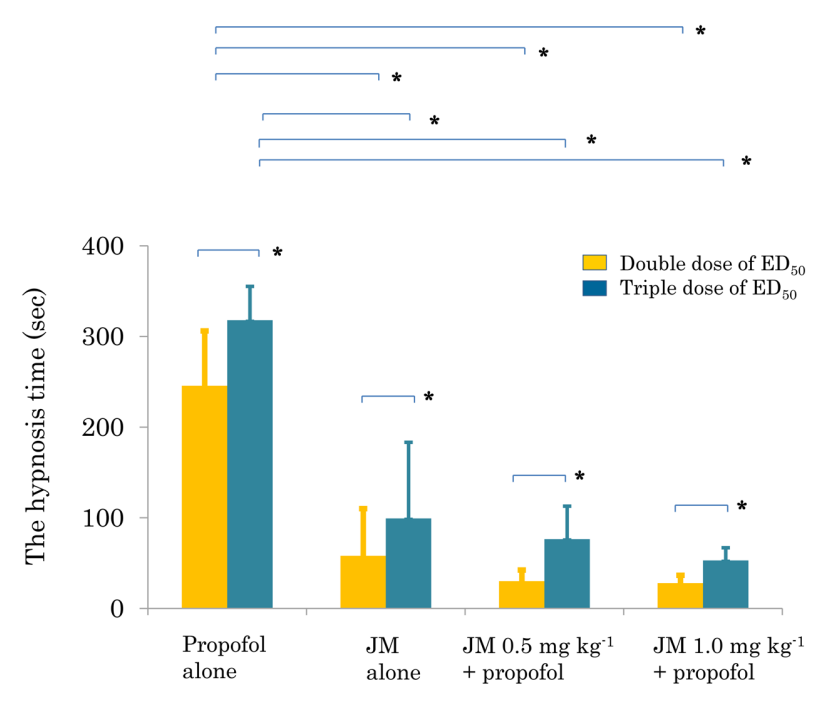

Fig. 2. Righting reflex recovery time after the first injection (anesthesia time). The data are demonstrated as mean and SD. All larger dose administrations prolonged anesthesia time. JM-1232(-) (JM) demonstrated a shorter recovery time and the mixtures demonstrated more prompt emergence from anesthesia. $\mathrm{ED}_{50}: 50 \%$ effective dose; JM: JM1232 $(-)$; *: $P<0.05$ between groups.

sists of hypnosis and analgesia. It is well known that the combination of multiple agents, such as anesthetics and opioids, synergistically enhances the potency of general anesthesia [16-18]. Although most studies have focused on interactions between hypnotics and analgesics, interactions within in the domain of hypnotics leaves room to search for new practices. On the other hand, multimodal analgesia using a combination of drugs has become popular in the field anesthesiology [19]. When the pharmacokinetics of each drug was not affected, the synergistic effect could reduce the each absolute dose of drug, thus, the reduced administration might shorten residual and extending effect not only after the first infusion but also after the multiple infusions.

Some barbiturate derivatives are associated with rapid recovery from hypnosis, but their repeated and prolonged administration delays emergence from anesthesia [20]. Combining drugs might provide not only supra-additivity but also quick recovery profiles independent of contextual uses of the anesthetics. JM1232(-) demonstrated a shorter recovery time than propofol at the first administration; however, the recovery time was prolonged with multiple injections and exceeded that of propofol. In contrast, the mixture of JM-1232(-) and propofol resulted in minimal prolongation of recovery time even after multiple injections.

Furthermore, flumazenil completely abolished the synergistic interaction, even after repeated injections of the combination, resulting in recovery of the pharmacodynamic profile. Although it is possible that flumazenil 


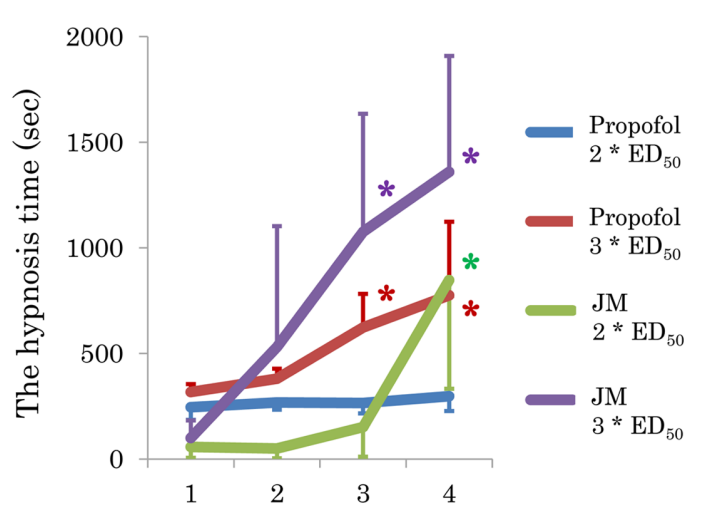

Injections of sole drug

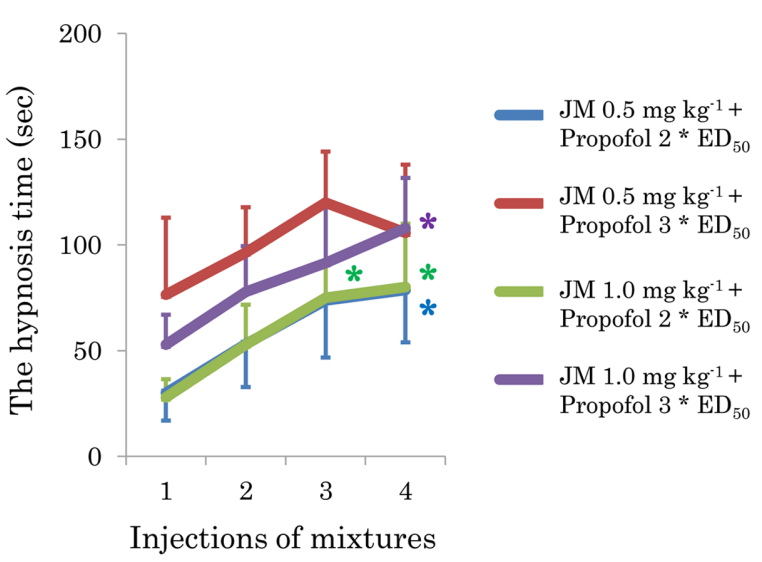

Fig. 3. Change in anesthesia time with repeated injections of 2- and 3-fold the $\mathrm{ED}_{50}$ doses of each of the study drugs, The data are demonstrated as mean and SD. JM-1232(-) (JM), propofol and mixtures of JM-1232(-) and propofol. Repeat injections significantly extended recovery time after the administration of JM-1232(-) and larger doses of propofol. *: $P<0.05$ vs. each anesthesia time after the first injection.
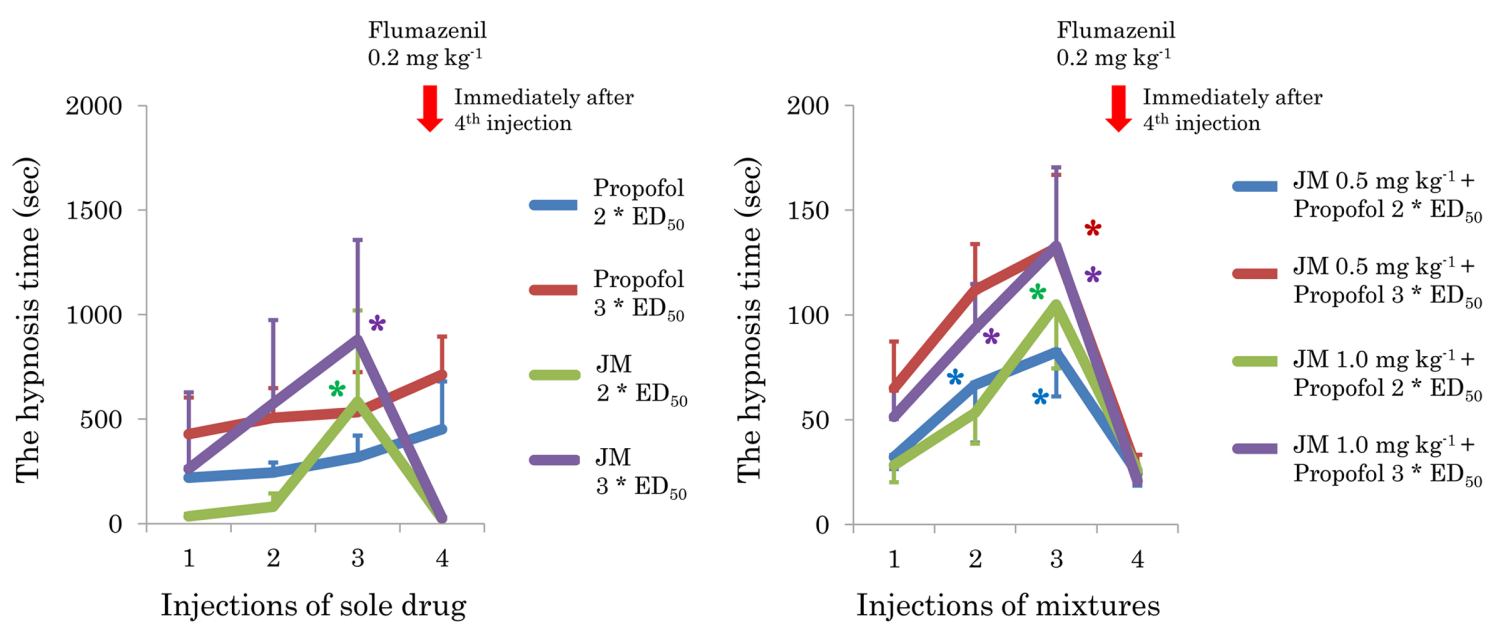

Fig. 4. Change in anesthesia time with repeated injections of 2- and 3-fold the $\mathrm{ED}_{50}$ doses of each of the study drugs, $\mathrm{N}-1232(-)(\mathrm{JM})$, propofol and mixtures of JM-1232(-) and propofol, and recovery with flumazenil. The data are demonstrated as mean and SD. Repeat injections significantly extended recovery time after the administration of JM-1232(-) and larger doses of propofol. Supplementary administration of flumazenil significantly shortened the recovery time except in the groups given propofol alone. ${ }^{*}: P<0.05 \mathrm{vs}$. each anesthesia time after the first injection.

might partially activate the benzodiazepine receptor $[21$, $22]$ and potentiate the hypnotic potency of anesthetics $[12,23]$, our results showed a sufficient reversal effect of flumazenil.

Diazepam is a popular benzodiazepine, but a lipophilic agent and insoluble in water, whereas midazolam is a water soluble benzodiazepine. However, our pilot experiments showed that the potency of midazolam in mice is very low, which is consistent to the results of Kilpatrick et al. [24]. Thus, the highly effective JM1232(-) was chosen as the supplemental drug for coadministration with propofol in the current investigation. Co-administration of midazolam decreases the time to achieve hypnosis without delaying emergence during short-term propofol anesthesia in daily clinical settings $[11,23]$. Not only JM-1232(-) but also other benzodi- azepines might well produce similar results to those seen in the present study. However, JM-1232(-) has a short duration of action, which makes it more suitable for use as a supplementary drug [25].

The limitations of the current study should be addressed. We could not predict the precise properties of the interaction; thus, the dose of the drugs and the sample size of the study were determined following the results of our previous investigation with extrapolation $[13,23]$. Another limitation was that we only evaluated the dose required to achieve hypnosis and the hypnosis time. Due to technical problems, the blood concentration of each drug was not determined. An electroencephalographic analysis might be useful to compare the synergistic effects of the drugs from a pharmacodynamic point of view [26, 27]. Finally, the volume of injection might be large for 
the animals. The results of the current drug interaction, however, might not be affected by the volume.

\section{Conclusions}

In summary, a new combination of JM-1232(-) and propofol demonstrated ultra-short-acting hypnotic effects. The supra-additive interaction could lead to the development of a new general anesthetic regimen with analgesics, including opioids. The new properties of the combination might be appropriate for every interventions requiring hypnosis.

\section{Ethics Approval and Consent \\ to Participate}

The study was approved by Animal Experiment Committee of Nagoya University Graduate School of Medicine, 26401. Consent to participate is not applicable for the study.

\section{Consent for Publication}

Not applicable for the study.

\section{Availability of Data and Materials}

The datasets used and/or analyzed during the current study are available from the corresponding author on reasonable request.

\section{Comflicts of Interests}

The authors declare that they have no competing interests

\section{Funding}

The part of the current investigation was funded by Grant-in-Aid for Scientific Research, Japan Society for the Promotion of Science, 25462902. The funder officialy gave the endowment after the review of the study protocol as competitive funds.

\section{Authors' Contributions}

ST performed the experiment, writing the manuscript. TT performed the experiment and writing the manuscript. MH helped to writing and correction of the manuscript and conducting the study. NM helped and directed study. MS organized the study and writing the manuscript. YUA conducted the study design, performed the experiments and data analysis, and writing the cur- rent manuscript. ASB directed the study and revised the manuscript. MO organized the study and examined pharmacological procedures. All authors have read and approved the manuscript.

\section{Acknowledgments}

JM-1232(-) was kindly gifted by Maruishi Pharmaceutical Co., Ltd. We appreciate the excellent support provided by Shiho Bakoshi, Director, Department of Central Research Laboratory, Maruishi Pharmaceutical Co., Ltd. We thank to Professor Koshi Makita, Chairman, Department of Anesthesiology, Graduate School of Medical and Dental Sciences, Tokyo Medical and Dental University, for supervising the manuscript.

\section{References}

1. Kanamitsu N, Osaki T, Itsuji Y, Yoshimura M, Tsujimoto H, Soga M. Novel water-soluble sedative-hypnotic agents: isoindolin-1-one derivatives. Chem Pharm Bull (Tokyo). 2007; 55: 1682-1688. [Medline] [CrossRef]

2. Wada T, Nakajima R, Kurihara E, Narumi S, Masuoka Y, Goto $\mathrm{G}$, et al. Pharmacologic characterization of a novel non-benzodiazepine selective anxiolytic, DN-2327. Jpn J Pharmacol. 1989; 49: 337-349. [Medline] [CrossRef]

3. Takamatsu I, Sekiguchi M, Yonamine R, Wada K, Kazama T. The effect of a new water-soluble sedative-hypnotic drug, JM1232(-), on long-term potentiation in the CA1 region of the mouse hippocampus. Anesth Analg. 2011; 113: 1043-1049. [Medline] [CrossRef]

4. Sneyd JR, Rigby-Jones AE. New drugs and technologies, intravenous anaesthesia is on the move (again). Br J Anaesth. 2010; 105: 246-254. [Medline] [CrossRef]

5. Sneyd JR, Rigby-Jones AE, Cross M, Tominaga H, Shimizu $\mathrm{S}$, Ohkura T, et al. First human administration of MR04A3: a novel water-soluble nonbenzodiazepine sedative. Anesthesiology. 2012; 116: 385-395. [Medline] [CrossRef]

6. Chidambaran V, Costandi A, D'Mello A. Propofol: a review of its role in pediatric anesthesia and sedation. CNS Drugs. 2015; 29: 543-563. [Medline] [CrossRef]

7. Campos S, Monteiro J, Valenzuela B, Gonçalinho H, de Pinho PG, Fresco P, et al. Evidence of Different Propofol Pharmacokinetics under Short and Prolonged Infusion Times in Rabbits. Basic Clin Pharmacol Toxicol. 2016; 118: 421-431. [Medline] [CrossRef]

8. Higuchi H, Adachi Y, Dahan A, Olofsen E, Arimura S, Mori T, et al. The interaction between propofol and clonidine for loss of consciousness. Anesth Analg. 2002; 94: 886-891. [Medline] [CrossRef]

9. Naguib M, Samarkandi AH, Moniem MA, Mansour ED, Alshaer AA, Al-Ayyaf HA, et al. The effects of melatonin premedication on propofol and thiopental induction dose-response curves: a prospective, randomized, double-blind study. Anesth Analg. 2006; 103: 1448-1452. [Medline] [CrossRef]

10. Adachi YU, Uchihashi Y, Watanabe K, Satoh T. Small dose midazolam or droperidol reduces the hypnotic dose of propofol at the induction of anaesthesia. Eur J Anaesthesiol. 2000; 17: 126-131. [Medline]

11. Adachi YU, Watanabe K, Higuchi H, Satoh T. A small dose of midazolam decreases the time to achieve hypnosis without delaying emergence during short-term propofol anesthesia. J Clin Anesth. 2001; 13: 277-280. [Medline] [CrossRef]

12. Adachi YU, Watanabe K, Higuchi H, Satoh T. High-dose 
flumazenil potentiates the hypnotic activity of propofol, but not that of thiopental, in ddY mice. Acta Anaesthesiol Scand. 2001; 45: 848-852. [Medline] [CrossRef]

13. Kimura-Kuroiwa K, Adachi YU, Obata Y, Kawamata M, Sato S, Matsuda N. Dexmedetomidine and hydroxyzine synergistically potentiate the hypnotic activity of propofol in mice. J Anesth. 2012; 26: 422-428. [Medline] [CrossRef]

14. Hendrickx JF, Eger EI 2nd, Sonner JM, Shafer SL. Is synergy the rule? A review of anesthetic interactions producing hypnosis and immobility. Anesth Analg. 2008; 107: 494-506. [Medline] [CrossRef]

15. Shafer SL, Hendrickx JF, Flood P, Sonner J, Eger EI 2nd. Additivity versus synergy: a theoretical analysis of implications for anesthetic mechanisms. Anesth Analg. 2008; 107: 507-524. [Medline] [CrossRef]

16. Johnson KB, Syroid ND, Gupta DK, Manyam SC, Egan TD, Huntington J, et al. An evaluation of remifentanil propofol response surfaces for loss of responsiveness, loss of response to surrogates of painful stimuli and laryngoscopy in patients undergoing elective surgery. Anesth Analg. 2008; 106: 471-479. [Medline] [CrossRef]

17. Syroid ND, Johnson KB, Pace NL, Westenskow DR, Tyler $\mathrm{D}$, Brühschwein $\mathrm{F}$, et al. Response surface model predictions of emergence and response to pain in the recovery room: An evaluation of patients emerging from an isoflurane and fentanyl anesthetic. Anesth Analg. 2010; 111: 380-386. [Medline]

18. Vereecke HE, Proost JH, Heyse B, Eleveld DJ, Katoh T, Luginbühl M, et al. Interaction between nitrous oxide, sevoflurane, and opioids: a response surface approach. Anesthesiology. 2013; 118: 894-902. [Medline] [CrossRef]

19. Mathiesen O, Rasmussen ML, Dierking G, Lech K, Hilsted KL, Fomsgaard JS, et al. Pregabalin and dexamethasone in combination with paracetamol for postoperative pain control after abdominal hysterectomy. A randomized clinical trial. Acta Anaesthesiol Scand. 2009; 53: 227-235. [Medline] [CrossRef]

20. Hughes MA, Glass PS, Jacobs JR. Context-sensitive half-time in multicompartment pharmacokinetic models for intravenous anesthetic drugs. Anesthesiology. 1992; 76: 334-341. [Medline] [CrossRef]

21. Belzung C, Le Guisquet AM, Crestani F. Flumazenil induces benzodiazepine partial agonist-like effects in BALB/c but not C57BL/6 mice. Psychopharmacology (Berl). 2000; 148: 24 32. [Medline] [CrossRef]

22. Smith BJ, Bickel WK. Flumazenil discrimination by humans under a two-response and a novel-response procedure. J Pharmacol Exp Ther. 1999; 291: 1257-1268. [Medline]

23. Adachi YU, Watanabe K, Higuchi H, Satoh T. Flumazenil reduces the hypnotic dose of propofol in male patients under spinal anesthesia. J Anesth. 2002; 16: 9-12. [Medline] [CrossRef]

24. Kilpatrick GJ, McIntyre MS, Cox RF, Stafford JA, Pacofsky GJ, Lovell GG, et al. CNS 7056: a novel ultra-short-acting Benzodiazepine. Anesthesiology. 2007; 107: 60-66. [Medline] [CrossRef]

25. Gill PS, Shah J, Ogilvy A. Midazolam reduces the dose of propofol required for induction of anaesthesia and laryngeal mask airway insertion. Eur J Anaesthesiol. 2001; 18: 166170. [Medline] [CrossRef]

26. Kenny JD, Westover MB, Ching S, Brown EN, Solt K. Propofol and sevoflurane induce distinct burst suppression patterns in rats. Front Syst Neurosci. 2014; 8: 237. [Medline] [CrossRef]

27. Solt K, Cotten JF, Cimenser A, Wong KF, Chemali JJ, Brown EN. Methylphenidate actively induces emergence from general anesthesia. Anesthesiology. 2011; 115: 791-803. [Medline] [CrossRef] 